\title{
Comparative Analysis on the Competitive Power of Vegetable Industry Elements in China
}

\author{
Xiaoli Zhang \\ Foreign Language Department \\ Shandong Institute of Business and Technology \\ Yantai, China
}

\begin{abstract}
Whether the basic factors are rich or not and whether they are used reasonably and efficiently are not only related to the production capacity of vegetable industry at present, but also related to the potential of future development of vegetable industry. This study selected the top 10 vegetable provinces in the national vegetable production total output in 2015, and compared the competitiveness level of the factors by calculating the above main factors of production factor endowment coefficient of each province.
\end{abstract}

Keywords—vegetable industry; factor competitiveness; factor endowment coefficient

\section{INTRODUCTION}

The competitiveness of the "factor level" can play a direct role in the formation of the final competitiveness of the industry, including the input of production capital elements, the quantity and quality of production organizations, quantity and quality of input of Labor factors, quantity and quality of natural resources such as land. Factor competitiveness is the necessary condition and foundation for the formation of final competitiveness, and it is an indispensable part of evaluating the level of overall industrial competitiveness. This study selected some representative areas and categories to describe the competitiveness of Shandong vegetable industry elements as well as environmental competitiveness, in which factor competitiveness is measured through the calculation of land, labor force, water resources and other factor endowment coefficients.[1]

\section{COMPARISON OF FACTOR ENDOWMENT CONDITIONS of MAJOR VEGETABLE PRODUCING PROVINCES}

"Table I" reflects the basic endowment of the main factors of vegetable production in 2015. Land factor endowment is measured by planting area of vegetables; labor factor endowment is measured by the number of rural employees; the factor endowment of water resources is measured by the effective irrigation area; capital factors are measured by the main amount of capital material used in agricultural production, including the amount of plastic film, diesel oil, pesticide, chemical fertilizer and so on. In 2015, the output value of agriculture, forestry, animal husbandry and fisheries in Shandong Province was 794.58 billion yuan, ranking the first; vegetable planting area of 1806.00 hectares also ranked the first; the number of rural employees, 36.952 million people, was less than Henan and Sichuan, ranking the third; the effective irrigation area of 5058.10 thousand hectare was less than Henan, ranking the second ; agricultural production of the main capital material consumption (agricultural plastic film, agricultural diesel, pesticide use, agricultural fertilizer use) less than Henan, ranked the second, which was 7.0715 million tons. In absolute scale, each factor endowment of Shandong Province has advantages, which has laid a good foundation for the development of vegetable industry.

TABle I. Factor Endowments of Main Vegetable Producing Provinces in China (2015)

\begin{tabular}{|c|c|c|c|c|c|}
\hline $\begin{array}{l}\text { Region ( Area } \\
\text { Sort ) }\end{array}$ & $\begin{array}{l}\text { Total output value of } \\
\text { Agriculture (\$100 million) }\end{array}$ & $\begin{array}{l}\text { Vegetable sowing area } \\
(1000 \mathrm{Ha})\end{array}$ & $\begin{array}{l}\text { Number of rural } \\
\text { employees }(\mathbf{1 0 , 0 0 0 0 )}\end{array}$ & $\begin{array}{l}\text { effective } \\
\text { irrigation area } \\
(1000 \mathrm{Ha})\end{array}$ & $\begin{array}{l}\text { Agricultural production of } \\
\text { major capital material } \\
\text { consumption }\end{array}$ \\
\hline Whole country & 89453.00 & 20353.00 & 48526.8 & 63036.40 & 8169.80 \\
\hline Shandong & 7945.80 & 1806.00 & 3695.2 & 5058.10 & 707.15 \\
\hline Hebei & 5340.10 & 1203.00 & 2731.8 & 4603.10 & 626.16 \\
\hline Henan & 6679.00 & 1730.30 & 4691.0 & 5205.60 & 812.85 \\
\hline Jiangsu & 5808.80 & 1323.40 & 2649.3 & 3929.70 & 456.50 \\
\hline Sichuan & 5433.10 & 1253.90 & 3762.3 & 2662.70 & 313.04 \\
\hline Hubei & 4732.10 & 1138.70 & 1797.6 & 2548.90 & 437.19 \\
\hline Hunan & 4904.10 & 1239.20 & 2898.2 & 2715.80 & 301.41 \\
\hline Guangdong & 4656.80 & 1229.20 & 2780.3 & 1874.40 & 334.51 \\
\hline Liaoning & 4062.40 & 487.10 & 993.5 & 1698.80 & 235.03 \\
\hline Guangxi & 3490.70 & 1075.40 & 2189.0 & 1541.30 & 312.87 \\
\hline
\end{tabular}




\section{FACTOR COMPETITIVENESS EVALUATION}

\section{A. Factor Endowment Coefficient}

The theory of "resource endowment" represented by Hecchelle-Orin model holds that countries with abundant labor force will take advantage of their comparative advantages to develop labor-intensive industries and products. And capital-rich countries will take advantage of their comparative advantages to develop capital-intensive industrial products. The trade pattern adapted to this pattern of production is that the labor - intensive countries export their labor - intensive products to capital - rich countries, while capital - rich countries export capital - intensive products to the labor - rich countries. The theory of Hecchelle-Orin applies the resource endowment coefficient to measure the abundance of a certain element in a country to determine whether it belongs to a country with abundant labor or capital-intensive countries. The formula for calculating the resource endowment coefficient is: (Vi/Vwi)/(Y/ Ywi), in which, VI: i resources owned by a country; Vwi: i resources of the world; Y : Gross domestic product of a country; Ywi: Total world gross domestic product. If the value of the coefficient is greater than 1 , it indicates that a country has the richness and abundance in the sense of H-O (Hexier-Orin) model on the i resource, whereas the other is the resource scarcity. It can be seen that the resource endowment coefficient of a country is the proportion of the i resource in the world and the share of the GDP in the world GDP. [2]

\section{B. Computing Result}

Based on the idea of calculating the resource endowment coefficient by using Hexier-Orin theory, We replace Vi with the total amount of resources in each province in a given year, replace Vwi with the total amount of resources in the country for a certain year, the total output value of agriculture, forestry, animal husbandry and animal husbandry in each province was replaced by Y, replace Ywi with the output value of Agriculture, Forestry, Animal Husbandry and Animal Husbandry in China. In this way, the resource endowment coefficient (or factor endowment coefficient) of the basic factors related to vegetable cultivation in each province in a given year can be calculated separately. The results of the calculation of the endowment coefficients of the major vegetable production provinces in 2015 are shown in "Table II".

TABLE II. FACtor Endowment CoefFicient of Main Vegetable Production Provinces in China Region

\begin{tabular}{|c|c|c|c|c|}
\hline Region & $\begin{array}{c}\text { Land endowment } \\
\text { coefficient }\end{array}$ & $\begin{array}{c}\text { labor endowment } \\
\text { coefficient }\end{array}$ & $\begin{array}{c}\text { Water resource } \\
\text { endowment coefficient }\end{array}$ & $\begin{array}{c}\text { Capital material endowment } \\
\text { coefficient }\end{array}$ \\
\hline Shandong & 0.999 & 0.857 & 0.903 & 0.974 \\
\hline Hebei & 0.991 & 1.100 & 1.354 & 1.318 \\
\hline Henan & 1.150 & 1.373 & 0.904 & 1.038 \\
\hline Jiangsu & 0.879 & 0.649 & 0.868 & 0.646 \\
\hline Sichuan & 1.013 & 1.518 & 0.724 & 0.733 \\
\hline Hubei & 1.043 & 0.549 & 1.099 & 1.603 \\
\hline Hunan & 1.050 & 1.556 & 1.028 & 0.665 \\
\hline Guangdong & 1.045 & 1.010 & 0.727 & 1.169 \\
\hline Liaoning & 0.454 & 0.410 & 1.039 & 0.805 \\
\hline Guangxi & 2.569 & 2.564 & 1.056 & \\
\hline
\end{tabular}

\section{CONCLUSION}

We find that the land endowment coefficient of Shandong Province is close to 1 (0.999), which is not as good as Guangxi, Henan, Hunan, Hubei and Sichuan. It shows that there are some bottlenecks in land space in the development of vegetable industry in Shandong; Shandong Province's labor resource endowment is less than 1 (0.857), less than Guangxi, Hunan, Sichuan, Henan, Hebei and Guangdong, ranking the seventh among the 10 provinces under investigation. On the one hand, it shows that as a large population province, the population in Shandong engaged in agricultural production and vegetable cultivation is shrinking and relatively scarce; on the other hand, it indicates that Shandong vegetable industry needs to develop deep processing production.

The actual situation confirms the above calculation results: at present, there are about 5, 000 vegetable processing enterprises in Shandong Province, ranking the first in the country in number. Among them, there are more than 500 processing enterprises that have the right to export vegetables independently, accounting for $1 / 3$ of the total number of vegetable export enterprises in China. The geographical position of the vegetable processing enterprises is relatively centralized, and four main processing areas have been formed, that is, Jiaodong processing Zone, mainly in Laiyang, Luzhong processing Zone in Anqiu, Southern Shandong processing Zone in Cangshan, and West Shandong processing Zone in Mudan District in Heze City, so that a certain industry cluster is formed. However, the processing of vegetables accounts for only $5 \%$ in the yield of vegetables in Shandong Province, a drop in the bucket and far from need. In addition, with the expansion of vegetable planting scale in Shandong Province, the vegetable transportation and marketing system in Shandong Province has expanded rapidly, and about 4 million people are engaged in vegetable marketing and circulation business. It can be seen that further development of downstream industries related to vegetable planting and raising the added value of vegetable products are the important ways to upgrade the vegetable industry in Shandong Province. Shandong's water resource factor is close to 1(0.903), less than Hebei, Hubei, Guangxi, Liaoning, Hunan and Henan, ranking seventh in the 10 provinces, which shows that Shandong Province belongs to the province of lacking water resources, and the development of vegetable industry suffers from the lack of water resources. Therefore, it is necessary to optimize the structure of 
vegetable varieties according to local conditions in order to adapt to the condition of water shortage; it is also necessary to increase the construction of farmland and water conservancy infrastructure in order to alleviate the bottleneck pressure of industrial development. Shandong Province's capital material endowment coefficient is close to 1 , at 0.974 , less than Hubei, Guangxi, Hebei and Guangdong, ranking the fifth among the 10 provinces in investigation. This level can only be considered as a moderate level, but in terms of the whole country, it is relatively high, which benefited from the popularization of facility vegetable, for example, greenhouse vegetable, and from large scale cultivation of featured vegetable. Generally speaking, the natural endowment of vegetable resources in Shandong is higher than those in the whole country, but it is at the middle level in the comparison of large provinces of vegetable production, so the basic resource advantage to promote the development of vegetable industry in Shandong is not significant. Shandong vegetable industry is facing the pressure of competition from other provinces; meanwhile, it also faces the pressure of industry transformation and upgrading. [3]

\section{REFERENCES}

[1] Zhu Zhiqiang, Zhang Xiaoli. An Analysis of the Contributing Factors to the Export Competitive Advantage of Shandong Vegetable Industry.[J].Modern Agricultural Science and echnology, ,2013,(12):267-268.

[2] Zhu Zhiqiang. Analysis of the basic characteristics of vegetable Industry Development in Shandong Province. [J] .North horticulture 8: 222-223.

[3] He Qiwei, Jiao Zigao, Zhou Xuyuan, Liu Shiqi. Shandong Vegetable Science and Technology Work Review and Suggestion [J]. China Vegetables, 2014, (1): 61-65. 